Volume 31, 2021

http://journals.sfu.ca/dwr

\title{
Article
}

\section{Constituting good citizen scientists within environmental citizen science discourse}

Philippa Spoel

Laurentian University

\section{Abstract}

Approaching citizen science discourse as a form of epideictic rhetoric, in this paper I explore how citizen scientists are rhetorically constituted through public-facing communication by five Ontariobased organizations involved in water-quality monitoring initiatives. Working from the perspective that it is important to consider both the macro-level (ideo)logics that frame these initiatives as well as their situated diversity and complexity, my analysis identifies shared and distinctive value-laden characteristics of the "good" water-monitoring citizen scientist interpellated by these organizations. This analysis contributes to our understanding of the shifting and complex interaction between governing logics and contextual specificities not only in the kinds of science that citizen-science programs pursue but also of the kinds of citizens that they value and constitute.

\section{Constituting good citizen scientists within environmental citizen science discourse}

In recent years, discourses of "citizen science" have proliferated within multiple fields of inquiry and across public, private, and civil society sectors. Within this multi-faceted rhetorical landscape, the value of citizen contributions to ecological research is strongly promoted, through programs ranging from wildlife and weather observations to water sample collection and air quality monitoring. This discourse is largely celebratory or, in rhetorical terms, epideictic: it promotes citizen science as "worthy of admiration" through language that presupposes, evokes, and thus increases adherence to the "common values" that it applauds (Richardson, 2018, p. 173; Perelman \& Olbrechts-Tyteca, 
1969). More specifically, it praises citizen science as a way of enriching environmental research and of enriching the citizens who participate in it (e.g., Dickinson et al., 2012; Kolok et al., 2011; Toomey \& Domroese, 2013; Chandler et al., 2017; Turrini et al., 2018). According to Kimura and Kinchy (2016), the main "virtues" of citizen participation in ecological research include "increasing scientific data; increasing citizens' scientific literacy and awareness; building community capacity for environmental protection; building more equal relationship between scientists and citizens; filling knowledge gaps and challenging official accounts; driving policy change; and catching polluters" (p. 331). In rhetorical terms, Kimura and Kinchy's (2016) framework elucidates the main "common values" applauded by the epideictic discourse of ecologically-focused citizen science. Notably, the "virtues" that they identify relate primarily to the kinds of science and science-related processes that citizen science makes possible: citizen science is "worthy of admiration" because it can advance scientific inquiry, foster scientific-environmental literacy, make science more participatory and democratic, and support science-based environmental protection and policy-making.

But what about the kinds of citizens, and citizen(ship) virtues, that citizen science initiatives both foster and presuppose? Within the literature on environmental citizen science, comparatively less attention has been paid to unpacking the multiple meanings and values implicitly attributed to the citizen side of the citizen-science equation. The question what does citizen science do for citizens (as well as for science) is to some extent addressed, but not the question who are citizen scientists expected and encouraged to be? Motivated by my ongoing interest in the rhetorical constitution of "citizen" values and identities within diverse environmental and health communication contexts, in this paper I draw on constitutive rhetorical theory to conduct a small, exploratory study of how the character of the good, or praiseworthy, citizen scientist is interpellated by a selection of Ontariobased civil society organizations involved in water-quality monitoring initiatives. While I use the phrase "good citizen scientist" to describe the figure constituted by this communication, this phrase is, in a sense, redundant since, consonant with citizen science's epideictic rhetoric of praise, to be a citizen scientist is to be "good." That is, this communication praises citizen scientists for "embodying what we value" not "what we deplore" (Segal, 2005, p. 61).

As articulated by Charland (1987), constitutive rhetorical theory attends to the ways in which subjects are constituted by the very discourses with which they are addressed. Working with Althusser's (1971) concept of interpellation or "hailing," Charland (1987) argues that individuals and groups are constructed as subjects discursively, producing an identity that is re-affirmed as they engage in action in the social world (p. 159). Charland (1987) refers to this as the "ideological 'trick"' whereby a communicative act constructs the identity of an audience that it simultaneously presumes 
to be pregiven and natural (p. 137). Constitutive rhetoric can apply in any context to transform addressees of discourse into subjects of that same discourse (Derkatch and Spoel, 2017). Investigating how citizen scientists are rhetorically constituted by my selected organizations contributes a distinctive perspective to rhetorical scholarship on citizen science, most of which has focused on the communicative processes and genres through which citizens participate in science knowledge-making (eg., Kelly \& Maddelena, 2016; Rea \& Riedlinger, 2016; Wynn, 2017).

This small study forms the initial stage of a more systematic and comprehensive proposed research program investigating the epideictic discourse of citizen science in Canadian-based ecological research. A preliminary search for citizen science initiatives in Canada revealed waterrelated research as a prominent area, with participatory water-quality monitoring initiatives forming the strongest sub-area within this general category ${ }^{1}$. For my purposes, the characterization of the initiative as "citizen science" was crucial, regardless of the precise type of water monitoring being conducted. In relation to my research focus on how the epideictic discourse of citizen science constitutes the identity of "good citizen scientists," participatory water monitoring (or, as it is also often called, "community-based" monitoring) is an especially interesting area to investigate because, unlike more institutionally-led and/or large-scale crowdsourcing citizen science programs, it appears to centre localized community concerns and objectives of civil society actors as impetus for undertaking citizen science research.

My decision to focus on the rhetoric of Ontario-based water monitoring initiatives for this initial exploration stemmed from the higher number of these programs that the preliminary search identified compared to other provinces. I selected five of the eight Ontario programs we found for further exploration based partly on their relatively strong on-line presence and partly on their diverse approaches to conducting and communicating about water-quality monitoring as citizen science. These organizations, which I introduce further below, are Citizen Scientists, EcoSpark, FOCA (Federation of Ontario Cottagers' Associations), Ottawa Riverkeeper, and Water Rangers².

This exploratory study aims to shed light on the situated complexities of what it means to be a good citizen scientist within participatory water monitoring projects and in so doing foreground the value of attending not only to the diverse meanings and practices of science within the expansive field of environmental citizen science but also to the textured characterizations of citizens, and of citizenship virtues, that this discursive field simultaneously presumes, invokes, and celebrates. I begin by providing some background on water-quality monitoring as a domain of community-based citizen science before analyzing how the public-facing communication of my selected organizations 
rhetorically constitutes the "good" citizen scientist according to both shared and distinctive characteristics.

\section{Citizen Science and Water Quality Monitoring}

Within the extensive arena of environmental citizen science, water-quality monitoring initiatives typically fall under the rubric of CBM (Community-Based Monitoring) or PEM (Participatory Environmental Monitoring) (Carlson \& Cohen, 2018; Conrad \& Hilchey, 2011; Kinchy et al. 2014; Starkey et al, 2017). As Carlson and Cohen (2018) explain, Involving communities in tracking freshwater quality and availability is often referred to as Community-Based Water Monitoring (CBM) ... This approach usually entails volunteers, either non-experts or trained scientists, engaging in one or more stages of collecting, analysing, and using data to answer locally-relevant questions. (p. 168)

CBM/PEM involves varying degrees of community collaboration with governments, industry, academic institutions, and/or civil society. Although not all CBM/PEM programs describe themselves as involved in "citizen science," their approach generally aligns with the concepts and practices of citizen science and community science (Carlson \& Cohen, 2018).

According to Conrad and Hilchey (2011), Lawrence's (2006) typology of public participation is especially helpful for thinking about the modes of citizen engagement in environmental governance that monitoring initiatives entail. These four modes are "consultative," meaning that members of the public contribute data or information to an authoritative body; "functional," which engages the public in decision-making as well as supplying information; "collaborative," where the public works closely with government in determining what is needed and in co-creating knowledge; and "transformative," where local people and affected communities make and implement their own research and decisions with support from experts as needed (Conrad \& Hilchey, 2011, p. 270). However, many CBM/PEM activities defy neat categorization into one mode or another (Conrad \& Hilchey, 2011, p. 276). My analysis draws on this typology to understand how the Ontario organizations I explored configure the role of citizen participation in water-quality monitoring.

I also draw on Kinchy et al.'s (2014) discussion of the "institutional logics" governing the citizen science activities of US-based civil society organizations monitoring watershed impacts of shale gas drilling to think through the main "logics" at work within Ontario-based citizen science water monitoring initiatives. Kinchy et al. (2014) found that the participatory water monitoring activities of the organizations they studied were guided by the logic of consciousness-raising through public engagement; the logic of science; and the logic of "environmental policing" (p. 259). These logics, they 
suggest, coincide with three different objectives that have historically guided the CBM/PEM field, namely "educating the public about conservation issues, producing scientific knowledge, and policing violations of environmental law" (p. 259). However, while these objectives may be common to the field as a whole, Kinchy et al. (2014) argue that the shifting ways in which they interact and compete within specific organizations and projects indicate the field's situated complexities and unsettled nature (p. 259). My analysis draws on and also extends this framework of "logics" within CBM/PEM to help illuminate situated differences as well as commonalities in how Ontario organizations rhetorically constitute their water monitoring programs and the citizens who participate in them.

While the specific motivations for citizen science water monitoring differ from place to place and project to project, the exigency "to fill gaps" in government and professional scientist-led monitoring is commonly cited as underlying many, if not all, initiatives (Carlson \& Cohen, 2018, p. 169). As Conrad and Hilchey (2011) explain,

The need to have a comprehensive understanding of ecosystem integrity ... is often confounded by a lack of, or inadequate and incomplete, data and monitoring initiatives by professional scientists and government agencies. To fill the void, nonprofessionals and citizen organizations have emerged the world over to track trends and to work towards effective and meaningful management planning, management, and stewardship. (p. 273)

Within the organizations I am looking at, Ottawa Riverkeeper most clearly names this exigency for its work, describing how a "huge gap in water quality information" about the Ottawa River exists because "There is not one government agency that continually collects water quality information on a wide-scale basis for analysis" (Ottawa Riverkeeper, n.d.-c).

According to Allen et al. (2018), community-based monitoring by citizens thus forms "an important piece of any water research framework" because it facilitates "a better understanding of watershed health and support[s] data-driven decision making" (p. 6). This perspective celebrates volunteer water monitoring as an empowering demonstration of how laypeople can contribute meaningfully to areas of research typically restricted to scientific experts and thus potentially influence environmental governance (Kinchy et al., 2014, p. 260).

Reliance on volunteer-based community groups and civil society actors to "fill gaps" in professional knowledge domains also can be linked to broader processes of neoliberalization. Kinchy et al. (2014) argue that the growing prevalence of CBM/PEM stems, at least in part, from neoliberal transformations to science and environmental governance (including budget cuts to basic science) which call for "vast amounts of unpaid work" from volunteer citizen scientists (pp. 261, 263; see also Lave, 2012). They contrast this to "activist-led PEM" (such as documenting pollution or 
contamination in a socio-economically disadvantaged community) which enables a more explicitly politicized, bottom-up scrutiny of science and the scientization of society (pp. 263-64). In this activist framework, citizens participate in environmental monitoring because it is one of the only ways they can gain knowledge of the problems they face and contest the claims of industrial [and/or government] opponents (Kinchy et al., 2014, p. 263).

Within the wide field of environmental citizen science, participatory water monitoring distinguishes itself by invoking explicitly community-oriented modes of citizen engagement. As such, it exemplifies an ideology of "neoliberal communitarianism" (van Houdt \& Schinkel, 2014; Rosol, 2012) which fosters modalities of "active" and "ethical" citizenship premised on the civic duty of voluntarily acting to support community well-being, frequently via civil society groups and projects (van Houdt \& Schinkel, 2014; Rosol, 2012; Rose, 2000).

As this brief background on citizen science water monitoring suggests, we can recognize macrolevel modes and (ideo)logics that inform these initiatives while also attending to the situational diversity and complexity of their specific goals, practices, and effects. Accordingly, my analysis of how five Ontario-based organizations rhetorically constitute their own versions of the "good" citizen scientist through their public-facing, on-line communication aims to identify specific, situated characteristics, while also observing how these particular rhetorical sites reconfirm and/or reconfigure broader logics and values. As explained above, I draw on Charland's (1993) theory of constitutive rhetoric to investigate how this communication discursively invokes value-laden characterizations of what it means to be a water-monitoring citizen scientist. The goal of this exploratory critique was to gather preliminary observations of how this communication explicitly or implicitly addresses and characterizes citizen scientists in verbal as well as, to a lesser extent, visual terms. To generate these initial observations, I focused on sections of their websites and, where applicable, facebook pages and web-linked resources (eg., pdf reports) which specifically mentioned citizen science and/or citizen scientists.

\section{Ontario-based Water Monitoring Organizations and Initiatives}

Before analysing how these organizations rhetorically constitute citizen scientists, I briefly explain each organization's overall mandate, its citizen science endeavours, and the public-facing communication materials on which my analysis is based. 


\section{Citizen Scientists}

On its website, Citizen Scientists (CS) describes itself as "a volunteer, not-for-profit group that focuses on ecological monitoring, environmental training and education" (n.d.-a). Since its establishment in 2001, it has been "monitoring stream health at various sites throughout the Rouge River watershed in Toronto and the GTA" (Citizen Scientists, n.d.-a). Its main partner is the Rouge Valley Conservation Centre. Although CS has initiated diverse monitoring projects, they all-as the organization's name implies-are designated as "citizen science." For my analysis, I therefore have looked at how the organization describes the main components of its work and addresses prospective volunteers on both its website and Facebook page.

\section{Ecospark}

EcoSpark (formerly Citizens Environment Watch) is, in its own words, "an environmental charity whose mission is to empower communities to take an active role in protecting and sustaining their local environment. We do this by giving people the tools for education, monitoring and influencing positive change" (EcoSpark, n.d.-a). Among the diverse programs that EcoSpark offers for schoolchildren in the Toronto area, "Changing Currents" is described as a "citizen science" program that invites teachers to "Connect your students to their local watershed through a hands-on water quality investigation" (EcoSpark, n.d.-b). My analysis focuses mainly on the webpages dedicated to this program.

\section{Federation of Ontario Cottagers' Associations (FOCA)}

The Federation of Ontario Cottagers' Associations (FOCA) is a not-for-profit organization whose mission is "to protect thriving and sustainable waterfronts across Ontario" (FOCA, 2018, p. 52) by representing volunteer lake associations and individual property owners in "cottage country" - that is, "the people who live at the waterfront, whether seasonally or year round" (FOCA, n.d.-a). FOCA encourages its members to become involved as "citizen scientists" in the Lake Partner Program, a province-wide, volunteer-based, water-quality monitoring program overseen by the Ministry of the Environment, Conservation, and Parks. Volunteers collect total phosphorus samples and make monthly water clarity observations on their lakes which are then sent to the Ministry's Dorset Environmental Science Centre for analysis (Dorset, n.d.). For my study, I focused mainly on FOCA's "Citizen Science - An Overview" webpage as well as their 52-page A FOCA guide to citizen science at the lake (2018). 


\section{Ottawa Riverkeeper}

Also founded in 2001, Ottawa Riverkeeper is a charitable organization operating under the international Waterkeeper Alliance model in which "each member group ... speaks for their body of water, advocating for its protection and health" (Ottawa Riverkeeper, n.d.-a). The organization describes itself as "a champion and collective voice for the Ottawa River watershed" (Ottawa Riverkeeper, n.d.-b). Through its volunteer "Riverwatch" program, Ottawa Riverkeeper supports local groups to address water problems related to their part of the watershed; this includes the option to conduct "citizen science" water-quality testing. To date, the most significant initiative of this kind has been Ottawa Riverkeeper's partnership project with Friends of Brewery Creek (FBC) which undertook "citizen science" water-quality testing of Brewery Creek (a 5km arm of the Ottawa River in the Hull-Gatineau area) over a five-year period to document the negative impacts of untreated sewage entering the creek from combined sewer overflows. For my analysis, I have focused on Ottawa Riverkeeper's website communication about this project along with their more substantive 2017 public report Brewery Creek and beyond: The problem with combined sewer overflows in Ottawa \& Gatineau.

\section{Water Rangers}

Unlike the preceding four organizations, Water Rangers does not itself directly run a specific citizenscience water quality monitoring project. Instead, Water Rangers is an "aquahacking" not-for-profit team created in 2015 whose mission is "to build the tools to help citizens and scientists easily record and analyse water data so that they can use the data to learn about problems, share discoveries and engage with their neighbours" (Water Rangers, n.d.-a). Water Rangers does this through its free digital app and data-sharing platform as well as low-cost "citizen science [test] kits" for monitoring water quality (Water Rangers, n.d.-d). My analysis focuses on how the organization's website communication about its "tools" constitutes citizen scientists (as opposed to focusing directly on how the app's digital interface or the testing equipment itself constitutes them).

How then do these five organizations rhetorically constitute the praiseworthy character of the citizen scientist? What valuable characteristics, or "virtues," are citizen scientists presumed and expected to hold and to demonstrate? While some of these characteristics appear common across the Ontario sites and projects I have selected, they also differ in noticeable ways. I begin by highlighting the main commonalities, then explore some of the differences. 


\section{Celebrating Common Values}

\section{Citizen scientists are motivated and have the means to contribute in a voluntary capacity to collecting water quality data.}

At the most fundamental, taken-for-granted level, these organizations constitute citizen scientists as individuals who both want and have the means to participate voluntarily in water monitoring initiatives. Consonant with neocommunitarian civic imperatives, they are responsible civil society actors who uncomplainingly and even enthusiastically work to address shortfalls in governmentfunded, professionally-staffed monitoring programs by voluntarily contributing their time, dedication, hard-work, curiosity, trainability, and willingness to collect water data.

The repeated references by these organizations to the "volunteer" dimension of their projects and membership underscores the centrality of this value to being a citizen scientist. Both Ottawa Riverkeeper and Citizen Scientists, for example, describe themselves as "volunteer driven" organizations, with the former relying on the "critical" work of their 70 volunteer "Riverwatchers" to protect the health of the river" (Ottawa Riverkeeper, n.d.-a). As a platform for recording and sharing water quality data, Water Rangers does not itself have volunteer members engaged in citizen science; however, it does argue that the platform is valuable because it can help groups who use it to "mobilize volunteers to make an impact on their watersheds" (Water Rangers, n.d.-a). Reassuring its readers that their participation in lake water monitoring is both strongly worthwhile and a civic obligation, FOCA refers to this volunteer work as an "under-appreciated form of public service," one that allows citizen scientists "to 'pay it forward' by carrying out the monitoring that must be done today in order to serve the needs of future generations" (FOCA, 2018, p. 4).

The common characterization of citizen scientists as "volunteers" implies that citizen science is open to everyone who wishes to participate. Indeed, Citizen Scientists states that "we do not turn away any volunteers. All are welcome and no experience is necessary ..." (Citizen Scientists, n.d.-b). However, this implication obscures the inherent selectivity and relative privilege of the kinds of citizens who make up the typical volunteer pool for different citizen science initiatives. For instance, volunteers must of course have time to carry out the work; in the case of water-quality monitoring, this typically means being able to make a fairly long-term commitment (ideally, several years) which suggests that volunteers are likely to enjoy a relatively stable residency in an area. Likewise, they must be able to access the relevant water body, and, as Citizen Scientists notes, "Volunteers must be able to work outdoors and in streams" (n.d.-b). As I discuss more below, volunteers also must be both 
interested in and able to understand at least some basic water science, if they do not already possess this knowledge ${ }^{3}$.

\section{Citizen scientists care deeply about and therefore seek to protect the health of their local waterways as environmental stewards.}

This second key characteristic actually incorporates two: first, citizen scientists have strong emotional attachment to "their" water: they care deeply about it and are (therefore) concerned about its health. This emotional connection forms the motivating ground for wanting to protect local waterways-in other words, to take ethical action as environmental stewards. For example, Ottawa Riverkeeper invokes an extensive base of concerned citizens as the motivating context for its work by declaring that, "Throughout the Ottawa River watershed, individuals and community groups are concerned about the health of the river and want to help to protect it" (Ottawa Riverkeeper, n.d.-c). For Water Rangers, its intended global community of citizen scientists encompasses the "many people out there who care about water;" these people are joined by a common "passion" that motivates them to want to "make an impact on their watersheds" (Water Rangers, n.d.-a). Like Ottawa Riverkeeper, FOCA posits its members' concern about the future health of the water they "love" as a fundamental characteristic, stating that, "First and foremost, lake association members are worried about the water. We all love our lakes and want to ensure that the activities and experiences today will be possible for future generations" (FOCA, 2018, p. 4). FOCA further identifies citizen scientists as environmental stewards when it states that "lake stewards (aka, citizen scientists)" are essential "in helping to improve and maintain the quality of Ontario's lakes" (FOCA, 2018, pp. 4-5).

The virtue of stewardship likewise informs Citizen Scientists' and EcoSpark's constitution of citizen scientists. One of Citizen Scientists' main goals is "To foster local stewardship ... with the hopes of shaping a more sustainable future" (Citizen Scientists, n.d.-a), while EcoSpark proclaims that its mission is "to empower communities to take an active role in protecting and sustaining their local environment" (EcoSpark, n.d.-a). Under this rubric, it invites "Students" to "Become a steward for green spaces in your community" and celebrates its new "Changing Currents-Branch Out Program" as connecting "your students" to both "citizen science AND stewardship" (n.d.-c). In these various ways, prospective citizen scientists are hailed and celebrated as people who share a strong emotional connection to water and hence a common concern about its health, and who therefore identify with the value of being water stewards. This configuration of the good citizen scientist aligns with the 
standard goal of fostering "sustained stewardship and conservation" that informs the wider field of community-based environmental monitoring (Kinchy et al., 2014, p. 263).

\section{Citizen scientists value contributing to the development of scientific knowledge and learning about science.}

This third shared characteristic links the ethical subjectivity of environmental stewardship with the epistemic values of helping to develop scientific knowledge about water quality while also improving personal scientific literacy. Taken together, these virtues reflect a combination of the "logic of science" and the "logic of consciousness-raising" which Kinchy et al. (2014) describe as primary organizing frameworks for the field of participatory water monitoring. As they explain, the logic of consciousness-raising-which links closely with the value of environmental stewardship-"stems from a widely-held idea that in a democracy, social change occurs through education of the citizens. Organizations guided by this logic pursue a strategy of environmental protection through increased public understanding and education about natural resources" (p. 268). The goal of producing scientific knowledge-as opposed to simply educating citizens about water-related environmental issues-indicates the logic of science that likewise typically motivates civil society organizations involved in PEM, though the degree of citizens' direct contributions to scientific-knowledge making is often quite restricted (e.g., it typically involves collecting data according to prescribed methods rather than participating directly in research design, analysis, theorization, and/or publication).

Both these epistemic logics appear to inform, in varying ways, the constitution of citizen scientists by Ontario organizations. For instance, Citizen Scientists describes itself as focusing on "ecological monitoring, environmental training and education"; it aims to "build [public/community] awareness and understanding of local aquatic ecosystems and their related issues" and also to train and engage volunteers to undertake water-quality monitoring that will contribute to this understanding (n.d.-a). Water Rangers presents its platform as a tool for "citizens and scientists to easily record and analyse water data so that they can use the data to learn about problems [and] share discoveries" (n.d.-a). The goal of EcoSpark's Changing Currents program to have grades 6-12 students "get outside, put on chest waders, explore a river or stream and learn about the importance of water quality through citizen science" (n.d.-b) foregrounds the logic of consciousness-raising and public education. FOCA's Guide to citizen science emphasizes the logic of science more, celebrating citizen scientists for their ability (as well as availability) to understand and undertake scientifically valid water-quality monitoring: "Having dedicated people who are able to take the time to measure physical 
characteristics of their lake, understand biological communities and assess chemical properties will play a vital role in keeping Ontario's lakes healthy" (FOCA, 2018, p. 4).

\section{Citizen scientists value community.}

This next value foregrounds the community engagement dimensions of citizen science water monitoring and indexes the communitarian ideology inherent to most, if not all, CBM/PEM projects. With the term "community" possessing a taken-for-granted honorific valence, the ideal citizen scientist is someone who values being engaged in a community of people who work together to protect their community's waterways. We see the prominence of this value in how Citizen Scientists identifies "Community Building" as one of its main objectives (n.d.-a) while Water Rangers has a whole page dedicated to "Building Communities" with the goal "to create spaces where we can empower communities to take care of their local waterways" (Water Rangers, n.d.-b). Interestingly, this description combines a conventional sense of community as place-based with the idea of a geographically-dispersed global community connected via the platform's virtual spaces. EcoSpark for its part prides itself on its "strong reputation" in the area of "community engagement" and it promotes the Changing Currents-Branch Out program as an opportunity for students "to discover nature in their community," "to participate in a community stewardship project," and "to take action in their community concerning what they discover" (EcoSpark, n.d.-c).

Ottawa Riverkeeper enacts the strongest and most explicitly place-based celebration of "community" when describing their citizen science work with Friends of Brewery Creek. The project's final report praises FBC for working to increase "community" awareness, appreciation, and enjoyment of the creek and describes the project as "an amazing demonstration of what can happen when a caring group of dedicated members of a community come together..." (Ottawa Riverkeeper, 2017, p. 9). By contrast, FOCA's Guide to citizen science configures a more attenuated and seemingly inverted relationship between citizen science and community. According to FOCA, "long-term monitoring creates a sense of community by keeping locals informed on changes to the health of their watershed." Here, "locals" are constructed as passive recipients of information they have themselves produced, rather than active citizens strengthening their sense of community by together monitoring their watersheds. Though strangely awkward, even illogical, this framing of "community" by FOCA aligns with its individualistic, privatized ideology, discussed further below.

I propose that the four characteristics discussed in this section form a generally shared set of values which the public-facing communication of these five Ontario organizations simultaneously presupposes and encourages as praiseworthy aspects of their citizen scientists. Identifying these 
attributes helps us to understand how being a good water-monitoring citizen scientist means much more than simply collecting water samples; it entails possessing and exhibiting a range of interconnected virtues that make up a textured, value-laden, and situated identity. These situated complexities become even more apparent when we consider some of the distinctive, rather than shared, ways in which these organizations interpellate their citizen scientists.

\section{Praising Distinctive Characteristics}

\section{Citizen Scientists}

The most distinctive aspect of Citizen Scientists' self-presentation is how its programs appear to be governed primarily by a logic of science; this presumes that the citizen scientists who participate in their various water monitoring programs are strongly, and mainly, concerned about ensuring the scientific "accuracy and reliability" of the data they collect according to the government-approved “Ontario Stream Assessment Protocol (OSAP)” (n.d.-a). Despite its inclusive organizational name and its "entirely volunteer-driven" nature, CS categorizes its types of citizen scientist into a three-level hierarchy: at the top end are the scientifically-expert though anonymous "Citizen Scientists" (the first-letter capitalization here an indicator of their leadership status) who run the organization and supervise the work of the (other) volunteers; these volunteers are themselves ranked into two levels: those who are "selected" each year by the organization to receive training and certification in the OSAP protocol and the volunteers whose work will be led (and monitored) by these more scientifically-certified citizens (n.d.-b). Thus, volunteer citizen scientists are praiseworthy because they help to monitor the Rouge River watershed but for this work to be valuable, they must be people who, in the first instance, respect the propriety of standardized Western scientific methods as well as the authority of established regulatory frameworks. And, even though the organization is not itself a government agency or regulatory body, volunteers must be satisfied that their role in water-quality monitoring is primarily contributory/functional - one of collecting and recording but not actively interpreting or directly acting on this data which, once collected, are "shared with government agencies, environmental organizations and researchers" (n.d.-a).

Citizen Scientists' mandate "To educate volunteers" similarly privileges an expert-led downstream approach focused on increasing citizens' scientific-environmental literacy:

Using in-class workshops and presentations and in-field training exercises, we educate and train the local community to collect accurate and reliable stream data . . . to build understanding and awareness about their local ecosystems.... Volunteers learn how and why stream monitoring is important and how it connects to environmental protection. (n.d.-a) 
This description separates the "We" who possess and transmit scientific knowledge from the volunteers who receive it. Volunteers are configured as lacking-and therefore requiringknowledge about how to collect "accurate and reliable stream data" and also-consonant with a logic of consciousness-raising-proper understanding of the environmental importance of water quality. Thus, the implied citizen scientist is someone who currently lacks relevant knowledge and understanding, but who is predisposed and possibly eager to learn from those who possess it.

\section{FOCA}

Like Citizen Scientists, FOCA's interpellation of its volunteers foregrounds their value in collecting accurate and reliable data that contributes to larger research programs led by government agencies. This is unsurprising given that FOCA's main citizen science endeavour is the province-wide Lake Partnership Program overseen by the Ministry of Environment, Conservation, and Parks. Like Citizen Scientists, FOCA emphasizes the importance for volunteer citizen scientists to follow "proper" water sampling procedures (FOCA, 2018, p. 12). The rhetorical shifts in the Guide between an inclusive, active characterization of FOCA's citizen scientists and a more distancing, impersonal address suggest a tension between a logic of community engagement/consciousness-raising and a logic of authoritative, regulatory science, with the latter appearing dominant. Thus, for instance, the Guide opens with the statement, "As citizen scientists, we can monitor our water resources to better understand and protect the health of our lakes (p. 9)" and references to "Our lakes and rivers" as well as "our future" occur intermittently throughout. But the Guide addresses its citizen scientist audience just as frequently in the third-person and the phrase "their lakes" occurs as often as "our lakes." Its use of passive voice to explain the value of the monitoring that citizen scientists conduct further reinforces the distance, and difference, between their role in collecting data and the role of government scientists in analysing and using this data: "Long-term data is useful because it allows a baseline and trends to be understood for a particular watershed. They also allow outliers or changes to be identified, as results can be checked against data from previous years" (p. 4). In this explanation, those who identify, check, understand, and use long-term data remain nameless; presumably, however, they are not the citizen scientists who have collected the data but instead the professional scientists at the province's Dorset Environmental Science Centre.

However, the most distinctive identifying feature of the citizen scientist interpellated by FOCA is their identity as a member of Ontario's cottage-community which means, in FOCA's framework, "a concerned citizen who owns waterfront property" (FOCA, n.d.-b). In other words, this person is a privileged private property owner who wishes to protect the health of their lake primarily to ensure 
its ongoing value for their family's recreational use and personal well-being. From this perspective, the Guide's appeal to future generations could be understood as, quite literally, referring to future generations who will inherit the family's cottage-property rather than to the future of global humanity which environmental discourse typically invokes. FOCA's slogan "Your Lake. Your lifestyle. Your legacy." as well as the "Cottage Succession" seminars that it offers to members support this interpretation (FOCA, n.d.-c). While images of people engaged in water-quality monitoring published by other organizations typically include group shots of fairly diverse-looking citizens, the cover of FOCA's Guide features a single grey-haired caucasian male alone in what is presumably his own boat on 'his' lake using a secchi disk to take a water clarity reading (FOCA, 2018, cover page). The repeated use of the phrase "your lake" in FOCA's Guide (along with the singular "the Lake" in its title) further constitutes this organization's citizen scientist as an individual motivated to participate in waterquality monitoring due to their private ownership stake in "the Lake." In this sense, extending Kinchy et al.'s (2014) three-logics framework, I would argue that, along with a logic of science, an individualistic (ideo)logic of private property ownership and investment is central to FOCA's citizen scientist discourse.

\section{Ottawa Riverkeeper}

Ottawa Riverkeeper also appeals to citizen scientists who care strongly about the health of their local waterway because of its "natural and recreational values;" this includes offering "city dwellers a much needed nature retreat" as well as a "playground" for paddling, fishing, water-side walking, and splashing and playing (Ottawa Riverkeeper, 2017, p. 2). However, unlike FOCA's private, individualistic framework, citizen scientists who engage in water monitoring of Brewery Creek are characterized as having a much more community-oriented attachment to place. They are motivated by the desire to work together to restore the health of their local waterway so that it can be enjoyed and appreciated by the whole community. In this way, Ottawa Riverkeeper's discourse aligns with a neoliberal communitarian ideology which promotes modes of active citizenship premised on the ethical imperative of individual citizens voluntarily taking responsibility for community well-being (van Houdt \& Schinkel, 2014; Rosol, 2012; Rose, 2000). In the case of Ottawa Riverkeeper, the motivating value of "community" includes not only working to support community well-being by attending to the health of its communal waterway, but also working together as a "community" to do so. Importantly, however, the inclusive connotation of the term "community" belies the selective and still individualistic nature of the active citizenship ideal which underlies this motivating discourse. 
Ottawa Riverkeeper's characterization of citizen scientists also contrasts FOCA's and Citizen Scientists' downstream, contributory/functional perspectives by naming "ordinary citizens" as leaders in determining the design, interpretation, and governance goals of their citizen science project. For instance, Ottawa Riverkeeper praises FBC as a "grassroots group" of "ordinary citizens" who have "worked hard to gain credibility as a community group able to discuss issues with their local elected officials" and who are using the results of their water quality research to "press for positive change for the Ottawa River" (Ottawa Riverkeeper, 2017, p. 9). The project's citizen scientists are constituted as people who identify problems, design and conduct research, and use results to implement change at a local-community level. In this way, their project has potentially transformative, not simply contributory, governance value.

This constitution of the good citizen scientist accords with Danielsen et al.'s (2010) finding that environmental monitoring schemes involving local people and related to local resource use are much more effective at influencing decisions than larger-scale, longer-term monitoring programs executed by scientists at regional, national, or international levels. They argue that particularly in lowerincome countries - though also, it seems, in at least one Canadian context—the monitoring schemes that inform decision-making and resource utilization at the local level are those which involve local people not only in the collection but also the analysis and interpretation of data (Danielsen et al., 2010, p. 1167). However, it is worth noting that the main (though not exclusive) governance influence that the Ottawa Riverkeeper/FBC project sought was to support the right of citizens to be informed about sewage overflows in order "to help swimmers, fishermen, paddlers and explorers make informed decisions about when to have contact with the river" (Ottawa Riverkeeper, 2017, p. 2); it was not (at least in the short term) directly advocating for these overflows to be prevented or reduced. Consonant with a rhetoric of information as empowerment, this right-to-know approach constitutes citizens as people who both can and should make their own informed choices about whether or not to use the waterway when health risks may be present. This framework presumes that citizens willingly accept personal responsibility for making "informed decisions" and also that they have the socio-structural capacity to do so.

\section{Ecospark}

Within EcoSpark's educational framework, students who participate in their programs are citizen scientists and environmental stewards in-the-making and their teachers are those who value both the educational and the environmental consciousness-raising dimensions of these programs. Pedagogically, EcoSpark's programming inculcates young citizens to possess a basic knowledge of 
water-quality monitoring and, more importantly, understand the civic imperative of becoming environmental stewards and acting to implement "change" in their communities. Hence the organization's slogan "Discover-Act-Change." Despite the seriousness of this imperative, the organization's upbeat, exclamation-mark-laden style interpellates young citizens, as well as their teachers, as people who want to have "fun" while learning about water-quality monitoring and being "inspired" (or "sparked") to influence "positive change." Notably, the exact nature of this "change" remains largely unspecified: the educational logic that governs EcoSpark's citizen science endeavours requires programming to be generic enough to engage students from multiple locations in the Greater Toronto area and to fulfill curriculum requirements for participating teachers.

\section{Water Rangers}

Water Rangers addresses its water-monitoring citizen scientists in a similarly upbeat, personalized style, replete with exclamation marks and friendly language, though the kind of citizen invoked of course differs from the young citizens being molded through EcoSpark's educational rhetoric. By comparison with the other water monitoring organizations, the most distinctive feature of Water Rangers' communication is how it interpellates a Millenial-type (and possibly also a Generation Ztype) of citizen scientist. This is apparent in how the organization's name alludes to "Power Rangers," a cultural reference most Millenials (at least North American ones) are very likely to comprehend: becoming a Water Ranger citizen scientist is like becoming a superhero Power Ranger, dedicated to fighting for the protection of water. This allusion likewise suggests that citizen scientists are motivated, at least in part, by a logic of environmental policing-not only "Power Rangers" but other "rangers" too are, by definition, people who patrol and guard specific places and resources.

Additionally, the Water Rangers site participates in what I would call a logic of gamification that further underlines its constitution of a Millenial/GenZ "digital native" type of citizen scientist (Thomas, 2011). For example, citizen scientists receive different badges as they proceed through various levels of using the platform, which a blogger for the Canadian Freshwater Alliance describes as highly motivating:

When I got back in front of my computer [after using the Water Rangers test kit], I found the sampling location on the map and uploaded the results to the application. To my delight, I got a badge for the task! . . . The second time I uploaded results, I got a "Trainee Location Guardian" badge. I was starting to feel like I was Mill Creek's water guardian! (Canadian Freshwater Alliance, 2018) 
The digital natives that Water Rangers addresses also value the ability to connect on-line with a global community of water-monitoring citizen scientists who are geographically but not technologically dispersed. But the kind of citizen scientist who values, and is validated by, Water Rangers' digital tools for water monitoring is not simply someone who welcomes and effortlessly uses an app to upload data in the service of a scientist-led research program. Like the "aquahacker" Water Rangers themselves, their implied citizen scientist is someone who strongly values opensource, accessible data-in other words, the ability to share data freely with a diverse global community of water quality monitors who operate beyond (though not necessarily against) the boundaries of institutional science. And this data collection/data sharing is valuable not only because of its openness and accessibility, but also because of its (potential) extent. As Water Rangers explains, "Our dream is to one day have millions of citizen water quality tests on our app from all around the world" (n.d.-a). Consonant with these values of open and extensive data sharing, Water Rangers claims that it facilitates "water testing for everyone" (n.d-c). Notably, though, this means "everyone" who can access and is comfortable using smart-phone apps and who feels at-home in on-line communities and communication, not to mention "everyone" who possesses the shared characteristics of the good citizen scientist discussed in the first section of my analysis.

\section{Conclusion}

This exploratory analysis of how five Ontario non-profit organizations rhetorically constitute their citizen scientists sheds light on the situated complexities of what it means to be a good citizen scientist within participatory water monitoring projects. By contrast with most discussions of citizen science within ecological research, this small study indicates the value of attending not only to the diverse meanings and virtues of science within the expansive, and expanding, territory of environmental citizen science but also to the multi-faceted and textured characterizations of citizens, and of citizenship virtues, that this discursive field simultaneously presumes, invokes, and celebrates. My preliminary exploration of the common and distinctive values invoked by these organizations in their characterizations of citizen scientists provides some initial insight into how the epideictic discourse of citizen science in ecological research not only celebrates the virtues of citizen science for research and for the citizens who participate in it; it also, more fundamentally but less obviously, praises the values that citizen scientists, as subjects and addressees of this discourse, are simultaneously presumed to possess and exhorted to demonstrate.

Because rhetorical criticism by definition illuminates situational specificities, this analysis does not present overarching conclusions about what it means to be a good citizen scientist engaged in 
water quality research; instead, it provides evidence of both the shared and differing citizen-scientist characteristics that are rhetorically applauded by these particular organizations in their publicfacing communication. My main hope is that this analysis confirms the situated complexities not only of the kinds of science that citizen science initiatives engage in but also of the kinds of citizens that these initiatives value and constitute, and that its preliminary findings suggest avenues for further critical research within rhetorical and social studies of science on the "citizen" dimension of "citizen science" as well as, more broadly, the celebratory discourse of citizen science.

Granted that no two (or more) organizations rhetorically constitute citizen scientists in identical ways, nonetheless my study suggests some shared normative features that raise questions about the kinds of people who do, and do not, fit the socio-politically situated ideal of the good citizen scientist within and possibly beyond the context of Ontario-based water monitoring endeavours. The virtues of volunteerism, environmental stewardship, science literacy, and community-mindedness underscore how the good citizen scientist enacts a socially, ethically, and epistemically selective mode of active citizenship. This mode combines neoliberal and communitarian expectations that individual citizens both value and have the capacity to take responsibility for self-improvement through personal education and consciousness-raising and also for their community's well-being through protecting the health of communal waterways. Notably, these virtues support the reliance on volunteer-based community groups and civil society actors to "fill gaps" in science knowledge primarily through the "unpaid work" of data collection (Kinchy et al., 2014). Even though these water-quality monitoring initiatives are in some senses community-based and participatory, the degree of scientific participation asked and expected of these citizen scientists is quite limited. Conversely, the degree of ethical and affective commitment that they are presumed and encouraged to possess is extensive: they are virtuous not only because they perform beneficial actions but, more fundamentally, because they strongly value volunteerism, community, and environment and they deeply care about their local waterways. Further, despite the differences in the kinds of citizen scientist interpellated by these organizations, for the most part they are constituted similarly as relatively (if not highly) privileged, non-adversarial individuals who have the means and motivation to fulfill, in FOCA's terms, a civic imperative of "public service." They are, as Carlson and Cohen (2018, citing Danielsen et al., 2005) note, people who inhabit relatively "affluent regions where monitoring can arise out of a culture of volunteerism and outdoor recreation," rather than socio-economically disadvantaged and/or isolated communities with "vulnerable livelihoods dependent on the preservation of ecosystems" (p. 169). 
With the partial exception of Ottawa Riverkeeper's FBC participants, they are not, in Kinchy et al.'s (2014) terms, citizens engaged in explicitly activist, politicized PEM aimed at scrutinizing and contesting industrial and/or state-led policies and practices that perpetuate social and environmental injustices (p. 263). Even the most politically activist and transformative project of the Ontario organizations I have examined-namely, the Ottawa Riverkeeper/FBC project-invokes citizens who have the luxury of choosing whether or not to access their local waterway for recreational (not essential) purposes when it is temporarily contaminated by sewage overflows. Despite the differences in the kind of citizen scientist who is at once constituted and celebrated by the five organizations analysed in this paper, as a whole the citizen who engages in water-quality monitoring in Ontario respects and seeks to work within and/or to expand, but does not actively oppose or disrupt, the institutional (ideo)logics of established regulatory and scientific structures. This characterization of the good water-monitoring citizen scientist in Ontario aligns with Kinchy et al.'s (2014) finding that, even within the highly controversial context of shale gas drilling, "the longstanding logics of consciousness-raising and science" which "prioritize public 'awareness' and scientific data collection, rather than overt political confrontation" continue to shape the efforts of civil society organizations to monitor watershed impacts (p. 284).

\section{Endnotes}

1. This preliminary search identified 147 ecologically-focused projects led by government agencies, universities, and/or NGOS, with a number of organizations leading several projects (eg., Birds Studies Canada; Nature Watch). We included any project that contained the phrase "citizen science" in its description, regardless of the project's exact nature. We classified 46 of these projects as somehow water-related, with the others focused mainly on land-based wildlife, plants, and insects.

2. I presented a preliminary version of this study at the June 2019 Conference on Communication and the Environment. Since then, most of the web pages have remained largely or exactly the same except the Water Rangers site which has been substantively revised including removing most of its explicit "citizen science" terminology (eg., its former page "Why citizen science?" has been changed to "Why water testing?"). These revisions foreground the continuously evolving nature of citizen science discourse.

3. See Blacker et al. (2021) for a discussion of the elitist, exclusionary, and increasingly corporateinfluenced nature of many citizen science endeavours. They note that the term "citizen science" may itself be problematic "because it suggests that citizenship might be a necessary prerequisite for 
participation in science, thereby marginalizing those denied citizenship, including refugees, immigrants, many Indigenous peoples and stateless people" (p. 11).

\section{References}

Allen, K., Colwell, R., \& Curran, D. (2018). Community-based water monitoring and decision-making. University of Victoria Environmental Law Centre. Retrieved from https://elc.uvic.ca/publications/cbm-water-monitoring/

Blacker, S., Kimura, A. H., \& Kinchy, A. (2021). When citizen science is public relations. Social studies of science. Advance online publication. https://doi.org/10.1177/03063127211027662

Canadian Fresh Water Alliance (2018, June 20). Water Rangers does citizen science [Blog]. Retrieved from https://www.freshwateralliance.ca/water_rangers_citizen_science

Carlson, T., \& Cohen, A. (2018). Linking community-based monitoring to water policy: Perceptions of citizen scientists. Journal of Environmental Management, 219, 168-177. https://doi.org/10.1016/j.jenvman.2018.04.077

Chandler, M., See, L., Copas, K., Bonde, A. M. Z., López, B. C., Danielsen, F., Legind, J.K., Masinde, S., Miller-Rushing, A. J., Newman, G., Rosemartin, A., \& Turak, E. (2017) Contribution of citizen science towards international biodiversity monitoring. Biological Conservation, 213 (B), 280-294. https://doi.org/10.1016/j.biocon.2016.09.004

Charland, M. (1987). Constitutive rhetoric: The case of the peuple québécois. Quarterly Journal of Speech 73.2, 133-150. https://doi.org/10.1080/00335638709383799

Citizen Scientists (n.d.-a). About us. Retrieved from http://citizenscientists.ca/About_Us.html

Citizen Scientists (n.d.-b). Volunteering. Retrieved from http://citizenscientists.ca/Volunteering.html

Citizen Scientists (n.d.-c). In Facebook [“About”] Retrieved from https://www.facebook.com/pg/CitizenScientistsToronto/about/?ref=page_internal

Conrad, C.C. \& Hilchey, K.G. (2011). A review of citizen science and community-based environmental monitoring: issues and opportunities. Environ. Monit. Assess., 176, 273-291. https://doi.org/10.1007/s10661-010-1582-5

Danielsen, F., Burgess, N.D., Balmford, A. (2005). Monitoring matters: examining the potential of locally-based approaches. Biodivers. Conservation, 14, 2507-2542. https://doi.org/ 10.1007/s10531-005-8375-0 
Danielsen, F., Burgess, N.D., Jensen, P.M., \& Pirhofer-Walzl, K. (2010). Environmental monitoring: the scale and speed of implementation varies according to the degree of people's involvement. J. Appl. Ecol., 47 (6), 1166-1168. www.jstor.org/stable/40958945

Derkatch, C. \& Spoel, P. (2017). Public health promotion of "local food": Constituting the selfgoverning citizen-consumer. Health, 21 (2), 154-170.

https://doi.org/10.1177/1363459315590247

Dickinson, J. L., Shirk, J., Bonter, D., Bonney, R., Crain, R. L., Martin, J., Purcell, K. (2012). The current state of citizen science as a tool for ecological research and public engagement. Front. Ecol. Environ. 10 (6), 291-297. https://doi.org/10.1890/110236

Dorset Environmental Science Centre (n.d.). Lake partner program. Retrieved from http://desc.ca/programs/LPP

EcoSpark (n.d.-a). About us. Retrieved from https://www.ecospark.ca/aboutus

EcoSpark (n.d.-b). Changing currents. Retrieved from https://www.ecospark.ca/changingcurrents).

EcoSpark (n.d.-c). Changing currents-Branch out collaborative. Retrieved from https://www.ecospark.ca/changing-currents-branch-out

EcoSpark (n.d.-d). Changing currents summary map. Retrieved from https://www.ecospark.ca/changing-currents-summary-map\#Disclaimer

FOCA (Federation of Ontario Cottagers' Associations) (n.d.-a). About. Retrieved from https://foca.on.ca/about/

FOCA (Federation of Ontario Cottagers' Associations) (n.d.-b). Citizen science - An overview.

Retrieved from https://foca.on.ca/citizen-science/

FOCA (Federation of Ontario Cottagers' Associations) (2018). A FOCA guide to citizen science at the lake. Retrieved from https://foca.on.ca/citizen-science/

FOCA (Federation of Ontario Cottagers' Associations) (n.d.-c). [home page] Retrieved from https://foca.on.ca/

Kelly, A. R., \& Maddalena, K. (2016). Networks, genres, and complex wholes: Citizen science and how we act together through typified text. Canadian Journal of Communication, 41, 287-303. https://doi.org/10.22230/CJC.2016V41N2A3043

Kinchy, A. J., Jalbert, K., \& Lyons, J. (2014). What is volunteer water monitoring good for? Fracking and the plural logics of participatory science. Political Power and Social Theory, 27, 259-89. https://doi.org/10.1108/S0198-8719_2014_0000027017 
Kimura, A. H., \& Kinchy, A. (2016). Citizen science: Probing the virtues and contexts of participatory research. Engaging Science, Technology, and Society, 2, 331-361.

https://doi.org/10.17351/ests2016.99

Kolok, A. S., Schoenfuss, H. L., Propper, C. R., \& Vail, T. L. (2011). Empowering citizen scientists: The strength of many in monitoring biologically active environmental contaminants. BioScience, 61(8), 626-630. https://doi.org/10.1525/bio.2011.61.8.9

Lave, R. (2012). Neoliberalism and the production of environmental knowledge. Environment and Society: Advances in Research, 3(1), 19-38. https://doi.org/10.3167/ares.2012.030103

Lawrence, A. (2006). 'No personal motive?' Volunteers, biodiversity, and the false dichotomies of participation. Ethics Place and Environment, 9(3), 279-98.

https://doi.org/10.1080/13668790600893319

Ottawa Riverkeeper (n.d.-a). Riverwatch program. Retrieved from https://www.ottawariverkeeper.ca/what-we-do-2/initiatives/riverwatchers/

Ottawa Riverkeeper (n.d-b). [Splash page]. Retrieved from https://www.ottawariverkeeper.ca/

Ottawa Riverkeeper (n.d.-c). Water quality and quantity. Retrieved from https://www.ottawariverkeeper.ca/ottawa-river-water-quality/

Ottawa Riverkeeper (n.d.-d). Who we are. Retrieved from https://www.ottawariverkeeper.ca/home/who-we-are/our-story/

Ottawa Riverkeeper (2017). Brewery Creek and beyond: The problem with combined sewer overflows in Ottawa \& Gatineau. Retrieved from

https://www.ottawariverkeeper.ca/publications/brewery-creek-and-beyond-the-problemwith-combined-sewer-overflows-in-ottawa-and-gatineau/

Rea, J. \& Riedlinger, M. (2016). Exigencies, ecologies, and internet street science. In M.J. Reiff \& A. Bawarshi (Eds.), Genre and the performance of publics (pp. 219-239). Utah State UP.

Richardson, J. E. (2018). Sharing values to safeguard the future: British Holocaust Memorial Day commemoration as epideictic rhetoric. Discourse \& Communication, 12(2), 171-191. https://doi.org/10.1177\%2F1750481317745743

Rose, N. (2000). Community, citizenship and "The Third Way." American Behavioral Scientist 43(9), 1395-1411. https://doi-org/10.1177\%2F00027640021955955

Rosol, M. (2012). Community volunteering as neoliberal strategy? Green space production in Berlin. Antipode, 44(1), 239-257. https://doi-org/10.1111/i.1467-8330.2011.00861.X

Segal, J. (2005). Health and the rhetoric of medicine. Carbondale: Southern Illinois UP. 
Starkey, E., Parkin, G., Birkinshaw, S., Large, A., Quinn, P., \& Gibson, C. (2017). Demonstrating the value of community-based ('citizen science') observations for catchment modelling and characterisation. Journal of Hydrology, 548, 801-817.

https://doi.org/10.1016/j.jhydrol.2017.03.019

Thomas, M. (2011). Deconstructing digital natives. New York: Routledge.

Toomey, A. H., \& Domroese, M. C. (2013). Can citizen science lead to positive conservation attitudes and behaviors? Human Ecology Review, 20(1), 50-67. https://www.jstor.org/stable/24707571

Turrini, T., Dörler, D., Richter, A., Heigl, F., \& Bonn, A. (2018). The threefold potential of environmental citizen science: Generating knowledge, creating learning opportunities and enabling civic participation. Biological Conservation, 225, 176-186.

https://doi.org/10.1016/j.biocon.2018.03.024

van Houdt, F. and Schinkel, W. (2014). Crime, citizenship and community: Neoliberal communitarian images of governmentality. The Sociological Review, 62(1), 47-67. https://doiorg/10.1111/1467-954X.12115

Water Rangers (n.d.-a). About. Retrieved from https://waterrangers.ca/en/about/.

Water Rangers (n.d.-b). Building communities. Retrieved from https://waterrangers.ca/act/building-communities/

Water Rangers (n.d.-c). [home page] Retrieved from https://waterrangers.ca/

Water Rangers (n.d.-d). Why citizen science? Retrieved from https://waterrangers.ca/en/whycitizen-science/.

Wynn, J. (2017). Citizen science in the digital age: Rhetoric, science, and public engagement. University of Alabama Press. 